\title{
Supporting Information \\ Photochemical ligation of DNA conjugates through anthracene cyclodimer formation and its fidelity to the template sequences
}

\author{
Toshihiro Ihara,* Tomohiro Fujii, Motoko Mukae and Akinori Jyo
}

Department of Applied Chemistry and Biochemistry, Faculty of Engineering, Kumamoto University, 2-39-1 Kurokami, Kumamoto 860-8555, Japan

E-mail: toshi@chem.kumamoto-u.ac.jp

\section{Synthesis of Anthracene-ODN conjugates}

ODN conjugates used in this study were synthesized according to Scheme1S.

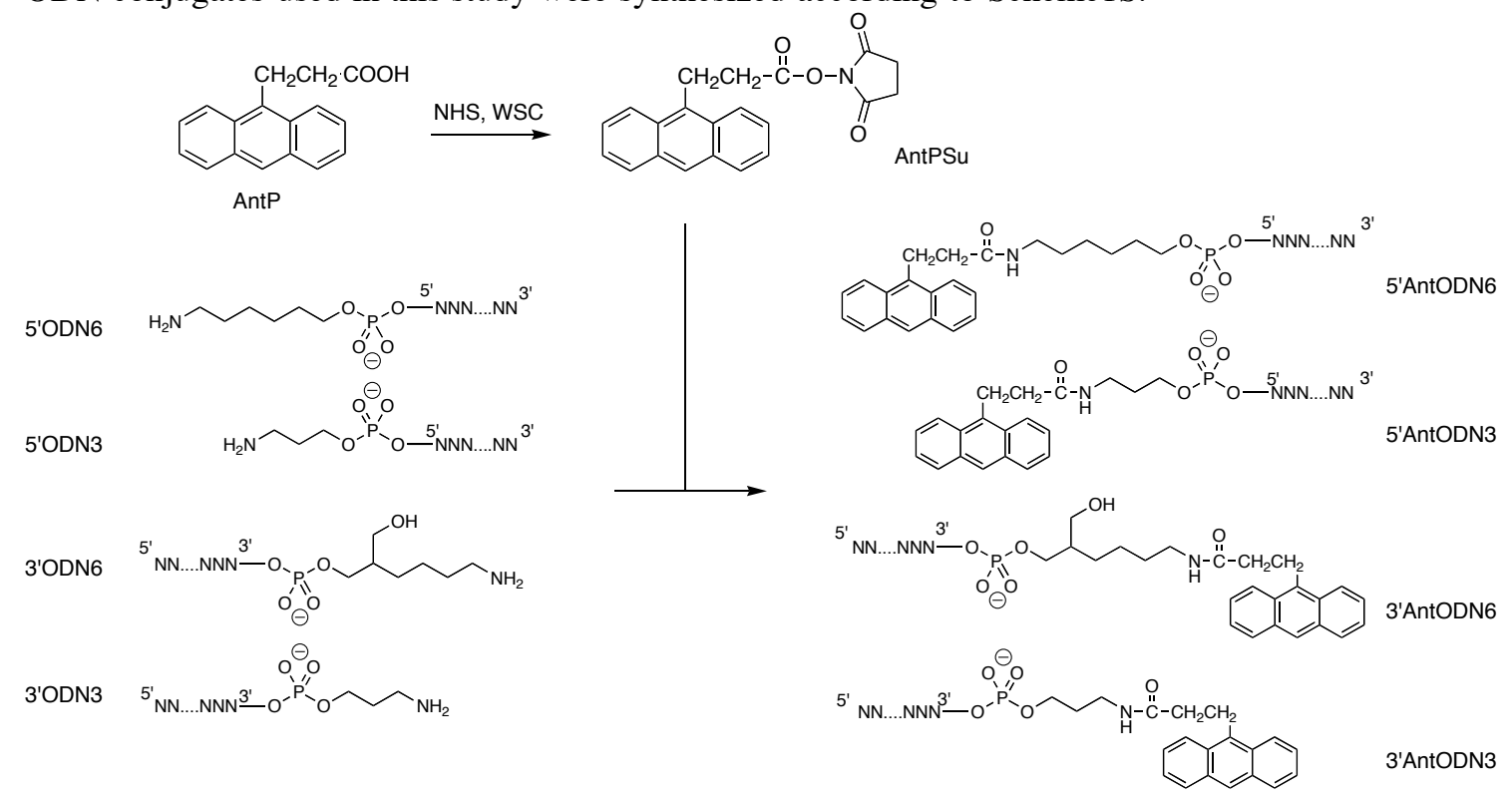

Scheme 1S. Synthesis of anthracene-ODN conjugates

Synthesis of AntPSu. A $25 \mathrm{~mL}$, three-necked, round-bottomed flask equipped with reflux condenser was charged with 9-anthracene propionate $(0.1 \mathrm{~g}, 0.4 \mathrm{mmol})$. The flask was evacuated before admitting argon gas. Acetonitrile $(2 \mathrm{~mL})$, N-hydroxysuccinimide $(0.09 \mathrm{~g}, 0.8 \mathrm{mmol})$, and 1ethyl-3-(3-dimethylaminopropyl)carbodiimide $(0.15 \mathrm{~g}, 0.8 \mathrm{mmol})$ were added into the flask. The reaction mixture was stirred and heated at $60-70^{\circ} \mathrm{C}$ for $4 \mathrm{~h}$ under argon. This solution was mixed with $50 \mathrm{~mL}$ dichloromethane and washed with water $(3 \times 50 \mathrm{~mL})$. The organic phase was dried $\left(\mathrm{Na}_{2} \mathrm{SO}_{4}\right)$, and evaporated to yield dark orange viscous oil which was chromatographed on silica $\left(\mathrm{CH}_{2} \mathrm{Cl}_{2}, R_{\mathrm{f}}=0.23\right)$ to afford $0.11 \mathrm{~g}(0.32 \mathrm{mmol}, 79 \%)$ of AntPSu as light orange solid.

${ }^{1} \mathrm{H}-\mathrm{NMR}\left(\mathrm{CDCl}_{3}, 400 \mathrm{MHz}\right): 2.89 \mathrm{ppm}(4 \mathrm{H}, \mathrm{s}), 3.08(2 \mathrm{H}, \mathrm{t}, J=8.54 \mathrm{~Hz}), 4.08(2 \mathrm{H}, \mathrm{t}, J=8.54 \mathrm{~Hz})$, $7.48(2 \mathrm{H}, \mathrm{t}, J=7.20 \mathrm{~Hz}), 7.56(2 \mathrm{H}, \mathrm{t}, J=7.60 \mathrm{~Hz}), 8.04(2 \mathrm{H}, \mathrm{d}, J=8.79 \mathrm{~Hz}), 8.26(2 \mathrm{H}, \mathrm{d}, J=8.79$ $\mathrm{Hz})$, and $8.40(1 \mathrm{H}, \mathrm{s})$

Synthesis of ODN conjugates. In a typical procedure, the purified amino-modified oligonucleotides, 5'ODN6 (30 nmol), were dissolved in $30 \mu \mathrm{l}$ of $0.2 \mathrm{M}$ Hepes buffer (pH 8.0). To this was added $60 \mu \mathrm{l}$ of a DMSO solution of AntPSu $(12.5 \mathrm{mM}, 750 \mathrm{nmol})$. After $10 \mathrm{~min}$ sonication of this mixture in which a light yellow precipitate appeared, the suspension was stirred at room temperature for $24 \mathrm{~h}$. Then, the solution was diluted to $200 \mu \mathrm{L}$ with $20 \%$ acetonitrile solution and chromatographed on a NAP10 column (Sephadex G-25, Amersham Biosciences). The obtained crude material was further purified by reversed phase HPLC. Judging from the peak area of the 
chromatogram, the reaction proceeded quantitatively. Other ODN conjugates were also synthesized by basically the same procedure.

MALDI-TOF/MS: Calcd. for [5'AntODN6]', 2147.51; found, 2147.60

Identification of the photoadduct of ODN conjugates.

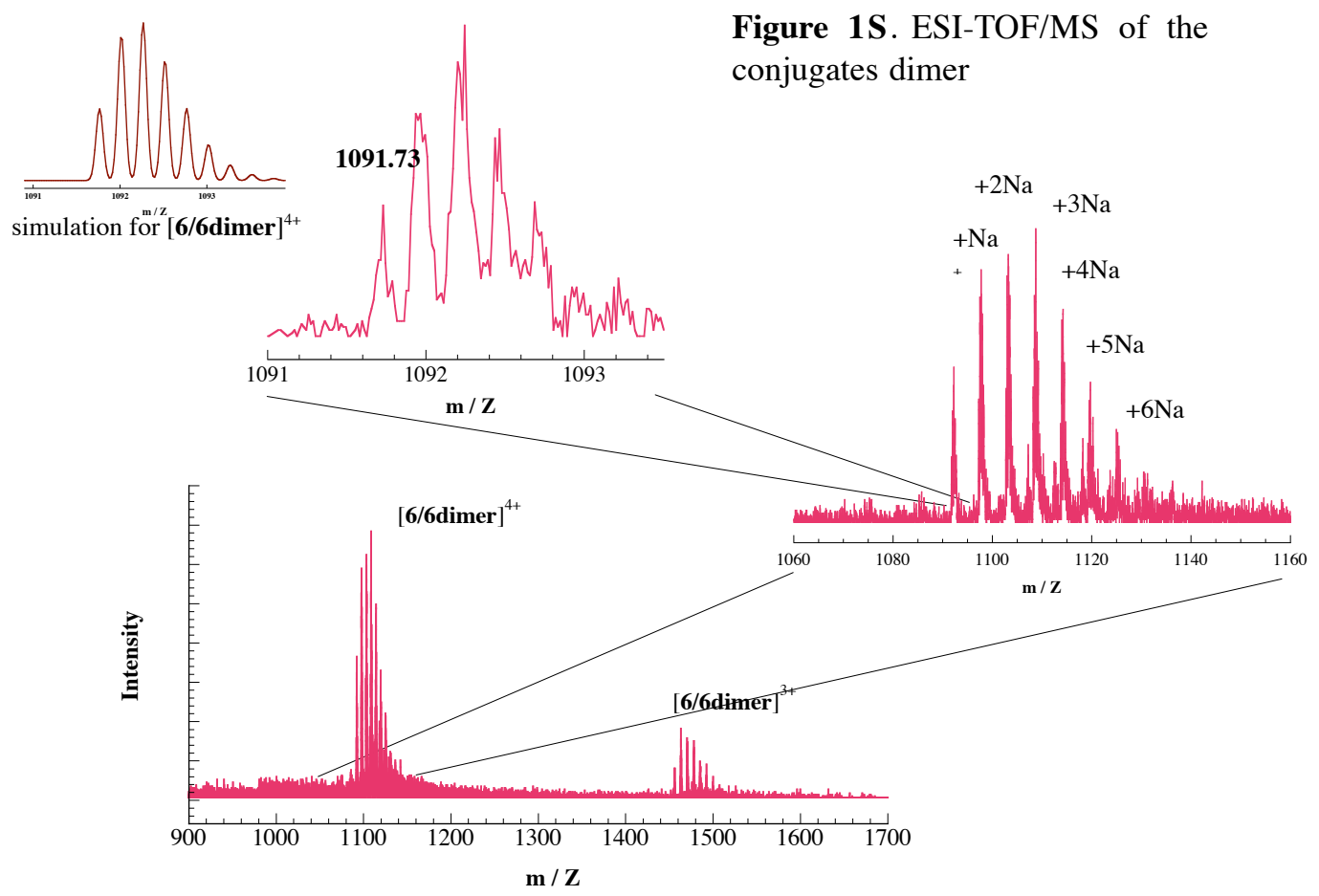


A new product that appeared at $t_{\mathrm{R}}=13 \mathrm{~min}$ after irradiation was collected and subjected to mass spectroscopic study. The spectra obtained by ESI-TOF/MS (Q-STAR, Amersham Biosciences) were indicated in Figure $1 \mathrm{~S}$. The $\mathrm{m} / \mathrm{Z}$ values of the peaks were identical to those calculated as conjugate dimer (m/Z: calcd. for [6/6dimer $]^{4+}$, 1091.76; found, 1091.73), and the peak patterns fitted with theoretical curve calculated from the abundance ratios of the constituent elements.

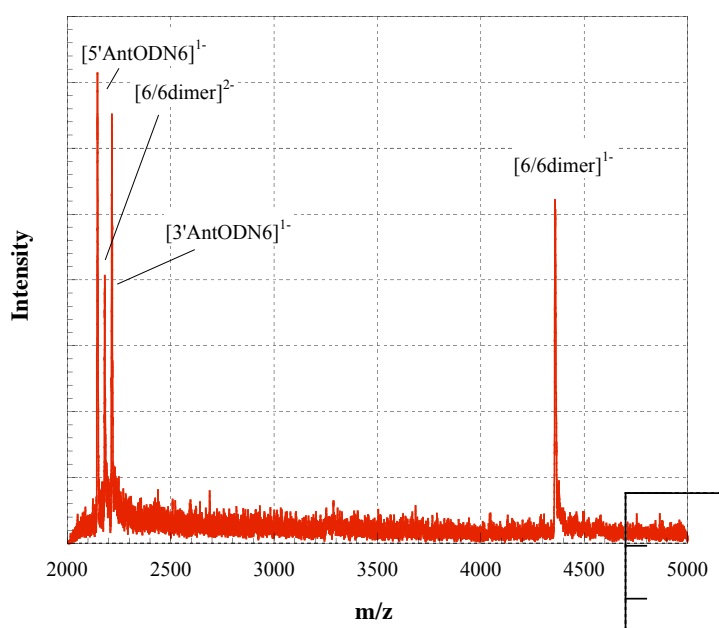

Figure 2S. MALDI-TOF/MS of the conjugates dimer

The dimer could be also identified by MALDI-TOF/MS (Voyager RP, Amersham Biosciences) (m/Z: calcd. for [6/6dimer]', 4364.03; found, 4362.05). The spectrum was indicated in Figure 2S. Laser irradiation for ionization split the dimer partially into two monomers, 5'AntODN6 and 3'AntODN6, probably through thermal process. It shows the reversibility of the chemical ligation presented here. 